\title{
$\widehat{A}$ Madridge
}

madridge Journal of Women's Health and Emancipation

interconnecting Scientific World

Research Article

Open Access

\section{Rational Choice, Obesity and Happiness: Overturning the Tyranny of Slenderness}

\author{
Manouchehr Mokhtari* and Elizabeth Pollock \\ School of Public Health, University of Maryland-College Park, USA
}

\section{Article Info}

\section{*Corresponding author:} Manouchehr Mokhtari

Associate Professor

School of Public Health

University of Maryland

$1142 \mathrm{SPH}$

College Park, MD 20742

USA

Tele: 301.405 .4014

E-mail: mokhtari@umd.edu

Received: September 3, 2018

Accepted: December 10, 2018

Published: December 19, 2018

Citation: Mokhtari M, Pollock E. Rational Choice, Obesity and Happiness: Overturning the Tyranny of Slenderness. Madridge J Womens Health Emancipation. 2018; 2(1): 51-55.

doi: $10.18689 / \mathrm{mjwh}-1000111$

Copyright: @ 2018 The Author(s). This work is licensed under a Creative Commons Attribution 4.0 International License, which permits unrestricted use, distribution, and reproduction in any medium, provided the original work is properly cited.

Published by Madridge Publishers

\begin{abstract}
This paper uses a rational choice framework to complement our understanding of the existing evidence and factors that are associated with obesity and happiness. Application of the rational choice model and the reinterpretation of the evidence allow for shedding light on the issues that escape researchers who only use psychosocial and sociodemographic factors for explaining obesity and happiness. The data analysis using a probabilistic model and a large nationally representative database show that higher income and more children, but not changes in the degree of obesity, are the significant and substantive contributors to happiness as defined by a satisfying relationship with a long-term spouse.
\end{abstract}

Keywords: Rational Choice; Obesity; Happiness; BMl; Income.

\section{Introduction}

In the past, social norms and social exchange theories have successfully contributed to our understanding of the psychosocial and sociodemographic factors that are associated with weight, mental health, appearance, and marital satisfaction [1-9].These theories and subsequent findings have provided the foundation for significant behavioral, policy and medical interventions to improve marital satisfaction $[5,10]$. While, social norm theory postulates on benefits of conformity and costs of nonconformity as drivers of action, social exchange theory rests on subjective cost-benefit analysis by rational actors. Despite these contributions, less attention has been paid to the ability of rational choice theory to incorporate mental health (or a state of depression), consumption, and the underlying economic environment. In this paper, we use a rational choice framework to complement the existing literature and provide an alternative interpretation of the data, thus, fill the existing void.

\section{A Rational Choice Model}

A rational choice approach posits that an individual maximizes satisfaction or utility $U$ subject to her limited resources. Given our intended analysis, we introduce a stress indicator $Z$ with a threshold $Z^{*}$ beyond which a woman is able to choose a consumption level $C$ that maximizes her marital satisfaction $U$. Let's assume that consumption level $C_{N}$ does not influence her body weight $W$, while $C_{O}$ does. Moreover, assume that body $W$ deceases if she consumes $C_{O^{\prime}}$ and that, $W$ also depends on her stress level $Z$. While facing an income level $I$, stress level $Z$, and prices $P_{N}$ for $C_{N}$ and $P_{O}$ for $C_{O}$, she maximizes her utility $U>Z^{*}$, which depends on $C_{N^{\prime}} C_{0^{\prime}} W$ and $Z$. That is,

$\operatorname{Max} U=U\left[C_{N}, W, Z\right]$

Given 


$$
\begin{aligned}
& \mathrm{W}=\mathrm{W}\left(\mathrm{C}_{\mathrm{O}^{\prime}} \mathrm{Z}\right) \\
& \text { and } \\
& \mathrm{I}=\mathrm{P}_{\mathrm{N}} \mathrm{C}_{\mathrm{N}}+\mathrm{P}_{\mathrm{O}} \mathrm{C}_{\mathrm{O}} .
\end{aligned}
$$

In the above, a priori, $\partial U / \partial C_{N}>0, \partial U^{2} / \partial C_{N}{ }^{2}<0, \partial U / \partial W<0$, $\partial U / \partial Z<0, \partial W / \partial C_{0}<0, \partial U 2 / \partial C_{0}{ }^{2}<0$ and $\partial W / \partial Z>0$. This utility maximization yields consumption levels that are increasing functions of income, i.e., $\partial C_{N} / \partial I>0$ and $\partial C_{0} / \partial I>0$. This framework shows that, while higher weight reduces our economic agent's marital satisfaction $\partial U / \partial W<0$, her utility $U$ $=U\left\{C_{N}(I), W\left[C_{O}(I), Z\right], Z\right\}$ still remains as a rising function of income $I$. This clearly implies that, income is the most crucial determinant of marital satisfaction. Thus, empirical models that exclude economics factors (income) are subject to misspecification bias and may indeed yield inconsistent estimates if income is correlated with other included factors (e.g., sociodemographic or psychosocial factors).

In addition to the implications of our rational choice framework, we also examine how increasing costs in a relationship affects marital dissatisfaction. While social norms theory explains the social significance of each variable in our analysis, marital exchange theory explains the negative and positive attributes of each variable. In other words, these two models highlight different effects that the interplay of mental health, physical health and physical appearance has on marital dissatisfaction, thus, leading to different hypotheses concerning the direction of the relationships among the variables. The social norms model emphasizes societal roles (optimal roles of good health, low depression, and normal body weight) and predicts that those who deviate from them will experience a higher level of marital dissatisfaction. The marital exchange model predicts that women with higher depression levels $Z^{*}$, lower physical health and higher body weight will be less dissatisfied in their marriages because they will evaluate their lowered health as decreasing their options in the marriage market and will, thus, be happier with their current relationship. An intensifying effect is added to the already proposed hypotheses through the concept of interdependence of factors - if the mental health, physical health and physical appearance of the wife all decline, then her marital dissatisfaction will increase even more. Therefore, the social norms and marital exchange theories predict opposite effects-social norms theory predicts a negative effect, and marital exchange theory predicts a positive effect on marital happiness.

\section{Methods}

This study was conducted using 2,279 and 1,831 observations from 1992 and 2002 rounds of the National Longitudinal Survey of Youth (NLSY) 1979, which is a multistage, stratified random sample of the adults in the United States. Ideally we would have preferred to use both the husband's and the wife's measures of marital satisfaction or dissatisfaction in our study. However, only the wife's marital satisfaction rating is available in NLSY. Despite this limitation, there have been some studies that have shown that information from wives is a better predictor of marital satisfaction, or dissatisfaction, than information from husbands [11].
In this study marital dissatisfaction was conditioned on indicators that are captured by poor mental health, poor physical health and poor physical appearance. Mental health was defined as the wife's level of depression, physical health as the wife's rating of her own health status, and physical appearance as an equation of body weight and height (BMI). We also include an indicator for the economic variable of interest (income), and control for socio-demographic and other relevant independent variables.

\section{Marital dissatisfaction}

The dependent variable was measured by responses to the question "Now, I have some additional questions about your current relationship. Would you say that your marriage is..." The respondents were asked to choose "1" very happy, "2" fairly happy, or "3" not too happy. A coding value of "4" was added to the marital dissatisfaction scoring for those respondents who had divorced from 1992 to 2002, because they were defined as being extremely unhappy.

\section{Income}

Income per family was measured and reported in dollars. This variable was directly extracted from the NLSY79 dataset. The sources of income variables consist of both earned and unearned (received) income for the household.

\section{Physical health}

This was measured by the question, "Would you be limited in the kind or amount of work you could do on a job for pay because of your health," to which respondents were asked to answer " 1 " yes, or "0" no.

\section{Mental health}

This was measured by the CES-Depression scale. The CESD scale asks nine questions, asking respondents, "After each statement, please tell me how often you felt this way during the past week...I did not feel like eating, my appetite was poor; I had trouble keeping my mind on what I was doing; I felt depressed; I felt that everything I did was an effort; my sleep was restless; I felt that I could not shake off the blues, even with help from my family or friends; I felt lonely; I could not get "going"; and I felt sad. For each of the questions, respondents were asked to answer: " 0 " rarely, none of the time, one day; "1" some, a little of the time, 1-2 days; "2" occasionally, moderate amount of the time, 3-4 days; or "3" most, all of the time, 5-7 days. The responses to the nine questions were summed, with the index of depression being an individual's total score, potentially ranging from 0-27. Cronbach's alpha was calculated for internal consistency in 1992 and in 2002 - both with high reliability (around 80\% in both years).

\section{Physical appearance}

The respondent's self-reported height and weight measurements were used to create her reported Body Mass Index (BMI) of weight/height ${ }^{2}$ in pounds and inches, i.e., BMI $=703 \times$ (weight in pounds/squared-height in inches) [12].

\section{Control variables}

There were four control variables in this study: length of marriage, children, and race. These were directly extracted from the NLSY79 dataset. 


\section{Results}

Using the 1992 and 2002 rounds of interviews from the NLSY79 dataset, the relationships between marital dissatisfaction, income, and mental health, physical health, and physical appearance were empirically examined. Either round of observations, 1992 or 2002, allows for preliminary testing of the stated hypotheses about the relationship between marital dissatisfaction and other variables on a cross sectional basis. Nonetheless, a stronger hypothesis-testing framework, which entails using the changes between 1992 and 2002 observations, was used to shed light on the hypothesized relationship between marital dissatisfaction and poor mental health, physical health, and physical appearance.

\section{Descriptive Statistics}

Tables 1 shows that, in 1992 , majority of $(80 \%=63 \%+17 \%)$ of married women rated their marriage as very happy or fairly happy. However, by 2002, a four percentage point decline in our indicator for the happily married women $(76 \%=56 \%+20 \%)$ is observed. Our results support previous findings that showed marital satisfaction declines over a normal course in relationships [13]. Almost a quarter reported they were not happy at all with their marriage. By 2002, around $20 \%$ had gotten divorced. As one may expect, this was a few percentage point (3 percentage points) higher than that of 1992. The decline in marital happiness coincides with a large real decline in family income of around thirty percent during 1992-2002 periods---nominal income declined less than two percentage points. Nonetheless, over the 1992-2002 decade, women's self-reported measure of mental health (CESD) became highly skewed to the left; i.e., suggesting becoming less depressed. This corresponds to tightening distribution of income during the same decade, since variations in family income (SD) declined by almost one-half (from 3,938.01 in 1992 to 1,859.94 in 2002).As one may expect, given the aging of respondents, our measure of physical health or physical limitation increased from 0.06 to 0.11 , indicating worsening physical health of the respondents. Similarly, the obesity or being overweight also experienced a rising trend over 1992-2002. In particular, the women in our sample became more overweight over the 1992-2002 decade. According to the BMI indicator, the average women was fit in 1992 (BMI of 24.86), but not in 2002 (BMI of 26.73), which is considered to be in the "overweight" category. Over the decade, both the sample mean and the sample standard deviation increased. This support other findings that show weight gains over the life-course $[2,13]$.

Table 1. Descriptive Statistics: The National Longitudinal Survey of Youth (NLSY79)

\begin{tabular}{|c|c|c|c|c|}
\hline & \multicolumn{2}{|c|}{1992} & \multicolumn{2}{c|}{2002} \\
\hline & Mean & Std Dev. & Mean & Std Dev. \\
\hline Marital Dissatisfaction & 1.72 & 0.03 & 1.86 & 0.03 \\
\hline very happy $=1,=0$ otherwise & 0.63 & & 0.56 & \\
\hline fairly happy $=1,=0$ otherwise & 0.18 & & 0.2 & \\
\hline not so happy $=1,=0$ otherwise & 0.01 & & 0.04 & \\
\hline extremely unhappy $=1,=0$ otherwise & 0.17 & & 0.19 & \\
\hline $\begin{array}{l}\text { Physical Health (limitation }=1,=0 \\
\text { otherwise) }\end{array}$ & 0.06 & 0.01 & 0.11 & 0.01 \\
\hline
\end{tabular}

\begin{tabular}{|l|c|c|c|c|}
\hline Physical Appearance (BMI) & 24.86 & 0.13 & 26.74 & 0.16 \\
\hline Mental Health (CESD) & 5.07 & 0.12 & 3.45 & 0.12 \\
\hline Income $(\$)$ & $63,923.13$ & 3938.01 & $63,093.22$ & $1,859.94$ \\
\hline Length of Marriage (years) & 9.92 & 0.1 & 9.91 & 0.12 \\
\hline Race (non-white = 1, =0 otherwise) & 0.12 & 0.01 & 0.12 & 0.01 \\
\hline Number of Children & 0.25 & 0.01 & 2.39 & 0.03 \\
\hline
\end{tabular}

Note: n (1992)=2279; n (2002)=1831; Std. = Linearized Standard Deviation.

\section{Overturning the Tyranny of Slenderness}

Literature indicate that higher income individuals are less likely to be obese than lower income individuals. Lower income individuals are less able to adhere to societal norms of being thin based on the notion that one's ability to control time, food quality, physical activity level, and stress levels are differentially associated with income. Since income can influence both body weight and marital satisfaction differently depending on the level of income, we use income variable to moderate the association between body weight and marital satisfaction. But, income also captures the most important contribution of the rational choice model to explaining happiness or satisfaction. Hence, income takes a direct role (beyond moderating impact) on happiness, thus, complementing psychosocial and sociodemographic explanations of marital happiness (or depression).

While marital exchange theory predicts that deterioration of the wife's health (higher depression, lower physical health), and appearance (higher BMI) decrease her marital dissatisfaction, social norms theory predicts the opposite deterioration of the wife's mental health, physical health and/ or physical appearance leads to an increase in her marital dissatisfaction. Hence, using ordered logistic regressions (OLR) marital dissatisfaction was modeled as a function of indicators for mental health, physical health and appearance, while controlling for certain other variables. The general model for this analysis could be summarized as:

Marital Dissatisfaction $=f$ (poor physical health, poor mental health, poor physical appearance, other variables)

where, 'other variables' included household income, race, length of marriage and number of children. Inclusion of these auxiliary variables controls for other extraneous factors that could also influence marital dissatisfaction.

Since the influence of weight gain or weight loss (physical appearance) on marital dissatisfaction could be different if respondents are very thin or very obese, this model was augmented by including squared values of the indicator for physical appearance (BMI). Similarly, because the theories in this study suggest that mental health may have an asymmetric impact on marital dissatisfaction, squared values of the mental health (CESD) variable were also included in the empirical model to capture this possible impact. Inclusion of squared values of the underlying variables - those that are predicted by intuition or other theoretical analysis-allows the researchers to incorporate potential nonlinear (or asymmetric) impacts on the dependent variable. However, retaining such nonlinear factors in the model will also depend upon their statistical significance, or their contribution to predicting the dependent variable. 
Our multivariate regression analysis (OLR) allowed for investigating the relationships between marital dissatisfaction and a number of indicators (above). For empirical implementation, marital dissatisfaction was coded from 1 to 4, where 1=very happy, $2=$ fairly happy, and $3=$ not too happy, and $4=$ =xtremely unhappy. Because of nonlinear influences on marital dissatisfaction from physical appearance and mental health, the quadratic transformations of BMI and CESD were also included in our model. Reported 1992 and 2002 OLR estimates in Table 2 associate mental health, physical health and physical appearance with marital dissatisfaction, while controlling for the number of children, income, race and length of marriage. Nonlinear terms for physical appearance and mental health and interaction terms for mental health, physical health and physical appearance, capture potential complexities in marital dissatisfaction. Estimates show that, while mental health and physical appearance are significantly associated with marital dissatisfaction, physical health is not. The estimated results show that, the BMI has a highly nonlinear association with marital dissatisfaction. For example, the nonlinearity of this association in captured by the estimates for 1992, where, the physical appearance appears to change sign while remaining statistically significant. Thus, our result soverturn the "tyranny of slenderness" [14-17], which hypothesis that the obsession with slenderness influences self-control, social status, and femininity [17] and the stigmatization of obesity [3]. Our analysis for 1992, which also supported for 2002, indicates that marital dissatisfaction decrease by gaining weight when woman is very thin person (BMl <20). On the other hand, beyond $\mathrm{BMI}=22$, marital dissatisfaction will initiate an upward trend. An Ordinary Least Square regression of marital dissatisfaction ( $\mathrm{Y}$ ) on $\mathrm{BMI}$ and $\mathrm{BMI}^{2}$ yields a relationship () that is captured in figure 1; thus, supporting the notion that the "tyranny of slenderness does not hold when complexities (nonlinearities) are taken into account. Our results (Table 2) also indicate that mental health (CESD) nonlinearly influences marital dissatisfaction. While mental health has an initial positive association with marital dissatisfaction $(t=3.80$, $p<0.01)$, its rise leads to a negative association ( $t=-2.55$, $p<0.01$ in this respect. This suggests mental health - marital dissatisfaction relationship is fairly complex. A rising CESD increases marital dissatisfaction to a point, at which, a decrease in marital dissatisfaction is observed. Over the course of 1992-2002, reported results in Table 2 also suggest that the number of children and length of marriage to negatively influence marital dissatisfaction. Specifically, while the length of marriage increases marital dissatisfaction in 1992, it decreases dissatisfaction a decade later (2002). This might be due to the fact that, couples with a higher marital satisfaction are those who stay together and, thus, are more represented in 2002 sample. However, self-identification of respondents with a minority group led to obtaining positive (negative) association with marital dissatisfaction (happiness).
Table 2. Weighted Ordered Logistic Regression (OLR) Estimates (Dependent Variable: Marital Dissatisfaction)

\begin{tabular}{|c|c|c|c|c|c|c|}
\hline \multirow[b]{2}{*}{ Variables } & \multicolumn{3}{|c|}{$1992(n=2279)$} & \multicolumn{3}{|c|}{$2002(n=1829)$} \\
\hline & \begin{tabular}{|c|} 
Coefficient \\
Estimate
\end{tabular} & t-value & $p$-value & $\begin{array}{l}\text { Coefficient } \\
\text { Estimate }\end{array}$ & t-value & $p$-value \\
\hline $\begin{array}{l}\text { Physical Appearance } \\
\text { (BMI) }\end{array}$ & $-0.23^{* *}$ & -3.91 & 0.00 & $-0.08^{* *}$ & -1.99 & 0.05 \\
\hline $\begin{array}{l}\text { Physical Appearance } \\
\text { Squared }\left(\mathrm{BMI}^{2}\right)\end{array}$ & $0.00^{\star *}$ & 3.74 & 0.00 & $0.00^{*}$ & 1.77 & 0.08 \\
\hline $\begin{array}{l}\text { Mental Health } \\
\text { (CESD) }\end{array}$ & $0.14^{\star \star}$ & 3.8 & 0.00 & $0.06^{\star *}$ & 3.34 & 0.00 \\
\hline $\begin{array}{l}\text { Mental Health } \\
\text { Squared (CESD²) }\end{array}$ & $-00.00^{* *}$ & -2.55 & 0.01 & -0.00 & -0.00 & 0.19 \\
\hline Physical Health (CPH) & 0.11 & 0.31 & 0.76 & 0.13 & 0.76 & 0.45 \\
\hline Number of Children & $-0.31^{\star *}$ & -2.55 & 0.01 & $-0.09 *$ & -1.70 & 0.09 \\
\hline Length of Marriage & $0.07^{\star \star}$ & 5.52 & 0.00 & -0.00 & -0.53 & 0.59 \\
\hline Race (nonwhite=1) & $1.16^{\star \star}$ & 10.01 & 0.00 & $0.78^{\star \star}$ & 6.12 & 0.00 \\
\hline CESD ${ }^{*} \mathrm{CPH}^{*} \mathrm{BMI}$ & -0.00 & -0.61 & 0.54 & -0.00 & -0.29 & 0.77 \\
\hline $\mathrm{CESD}{ }^{\star} \mathrm{CPH}$ & 0.00 & 0.37 & 0.71 & $0.00^{* *}$ & 3.23 & 0.00 \\
\hline Income & $<-0.01^{* *}$ & -2.93 & 0.00 & -0.00 ** & -6.48 & 0.00 \\
\hline
\end{tabular}

Notes: * significant at $10 \%$; ${ }^{* *}$ significant at $5 \%$.

1992 sample size, $\mathrm{n}=2279$

2002 sample size, $\mathrm{n}=1829$

F-test for 1992: $F(11,2268)=24.41$, Prob $>F=0.00$.

F-test for 2002: $F(11,1818)=16.16$, Prob $>F=0.00$

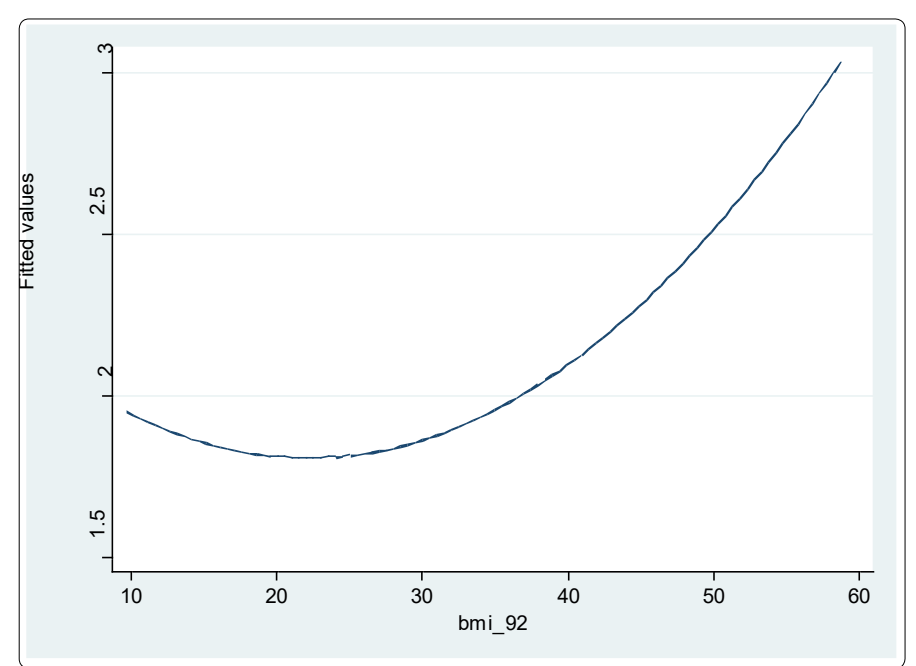

Figure 1. The Nonlinear Relationship between Marital Dissatisfaction and Physical Appearance in 1992

Key: Fitted Values = Marital Dissatisfaction Variable; bmi_92 = Physical Appearance Variable

A critical component of economic way of thinking (rational choice) consists of the reaction of economic agents (in this case, women) to the underlying economic variables, e.g., income and prices. Our sample provides a valuable opportunity to investigate the impact of income on marital dissatisfaction. Table 2 shows that, for both 1992 and 2002, reaction of marital dissatisfaction to income supports the rational choice hypothesis, which underpins our model (the above optimization exercise). Estimated coefficients for income are negative and statistically significant for both 1992 and 2002 samples. This implies that the higher is the household income, the less dissatisfied are women with their marriages. Thus, our results provide strong evidence for supporting the rational choice approach to marital satisfaction or happiness. 


\section{Discussion}

This paper develops and applies a rational choice framework model that complements the conventional analysis of the data for shedding light on the intricate issues that explain obesity and happiness (especially, marital satisfaction). The data analysis show that higher income and more children, but not changes in the degree of obesity, are the significant and substantive contributors to happiness as defined by a satisfying relationship with a long-term spouse. Additionally, this research sheds light on a number of interrelated issues that provide significant contrast with the past findings. While previous research has found that men place a great deal of importance on a woman's body size and shape when they initiate romantic relationships $[2,18]$, the current study rejects this notion. Previous studies ascertain that married couples do not need to attract a partner, thus, do not feel obligated to control their eating and/or conduct exercises that would make them physically fit $[2,6]$.This notion, a priori, point to significant estimates for the physical appearance in our analysis. However, recent research shows that medical interventions (bariatric surgery) that lead to reduced obesity and improved appearance still do not yield significant improvement in marital satisfaction [10]. This might be due to the fact that, after marriage changes in body weight have no effect on changes in marital dissatisfaction.

\section{Conclusion}

This paper uses a rational choice framework for further shedding light on the issues that escape researchers who only use psychosocial and sociodemographic factors for explaining obesity and happiness. The data analysis using a probabilistic model and a large nationally representative database show that higher income, years of marriage, and more children are substantive contributors to happiness as defined by a satisfying relationship with a long-term spouse.

\section{References}

1. Allon N. The stigma of overweight in everyday life. In B. B. Woldman (Ed.), Psychological aspects of obesity. New York: Van Nostrand Reinhold, 1982; 130-174.

2. Averett SL, Sikora A, Argys L. For better or worse: Relationship status and body mass index. Econ Hum Biol. 2008; 6(3): 330-349. doi: 10.1016/j. ehb.2008.07.003

3. Carr D, Friedman MA. Is obesity stigmatizing? Body weight, perceived discrimination, and psychological well-being in the United States. $J$ Health Socl Behav. 2005; 46(3): 244-259. doi: 10.1177/002214650504600303

4. Ingoldsby BB, Smith SR, Miller JE. Exploring Family Theories. Los Angeles: Roxbury, 2004.

5. Kuroki M. Life satisfaction, overweightness and obesity. International Journal of Wellbeing. 2006; 6(2): 93-110. doi:10.5502/ijw.v6i2.519

6. Meltzer AL, Novak SA, McNulty JK, Butler EA, Karney BR. Marital satisfaction predicts weight gain in early marriage. Health psycho. 2013; 32(7): 824-827. doi: 10.1037/a0031593

7. Millman M. Such a pretty face: being fat in America. New York: Norton, 1980.

8. Sobal J, Rauschenbach B, Frongillo E. Obesity and marital quality: Analysis of weight, marital unhappiness, and marital problems in a U.S National sample. Journal of Family Issues.1995; 16(6): 746-764. doi: 10.1177/019251395016006004

9. White J, Klein D. Family Theories 2nd edition. California: Sage Publications; 2002.

10. Ghanbari Jolfaei A, Lotf, T, Pazouki A, Mazaheri Meybod A, Soheilipour F, Jesmi F. Comparison between Marital Satisfaction and Self-Esteem Before and After Bariatric Surgery in Patients with Obesity. Iran J Psychiatry Behav Sci.2016; 10(3): e2445. doi:10.17795/ijpbs-2445

11. Gottman JM, Levenson RW. A two-factor model for predicting when a couple will divorce: Exploratory analyses using 14-year longitudinal data. Fam Process. 2002; 41(1): 83-96.

12. Fu H, Goldman N. The association between health-related behaviours and the risk of divorce in the USA.J Biosoc Sci. 2000; 32(1): 63-88.

13. Dinour $L$, Leung $M$, Tripicchio $G$, Khan $S$, Yeh $M$. The association between marital transitions, body mass index, and weight: A review of the literature. Journal of Obesity. 2012; 1-16. doi:10.1155/2012/294974

14. Bartky SL. Femininity and domination: Studies in the phenomenology of oppression. New York: Routledge; 1990.

15. Bordo S. Unbearable Weight: Feminism, Western Culture, and the Body Berkeley: University of California Press; 1993.

16. Benjamin $\mathrm{O}$, Kamin-Shaaltiel $\mathrm{S}$. It's not because I'm fat: Perceived overweight and anger avoidance in marriage. Health Care Women Int. 2004; 25(9), 853871. doi: 10.1080/07399330490493403

17. Baker M. The family: Changing trends in Canada. Toronto: McGraw-Hill. 1984.

18. Singh $D$. Female judgment of male attractiveness and desirability for relationships: Role of waist-to-hip ratio and financial status. J Pers Soc Psychol. 1995; 69(6), 1089-1101. 